\title{
PENATAAN KAWASAN WISATA PANTAI PANGUMBAHAN DENGAN KONSEP EKOWISATA
}

\author{
Stanley Waworuntu ${ }^{1)}$, Suryono Herlambang ${ }^{2)}$ \\ 1)Program Studi S1 PWK, Fakultas Teknik, Universitas Tarumanagara, stanley.345150007@stu.untar.ac.id \\ 2)Program Studi S1 PWK, Fakultas Teknik, Universitas Tarumanagara, suryonoh@ft.untar.ac.id
}

\begin{abstract}
Abstrak
Pantai Pangumbahan merupakan salah satu pantai yang terletak di selatan Pulau Jawa,, tepatnya di Desa Pangumbahan, Kecamatan Ciracap, Kabupaten Sukabumi, Provinsi Jawa Barat. Pantai ini merupakan wilayah perencanaan dan pembangunan wisata bahari di dalam RIPPARDA (Rencana Induk Pembangunan Kepariwisataan Daerah) berdasarkan Perda Kab. Sukabumi No. 10 Tahun 2010 pasal 49 serta memiliki keunikan yang belum tentu dimiliki oleh pantai lain seperti atraksi pelepasan tukik, karakter ombak yang sesuai dengan olahraga surfing, Karakter ombak di beberapa titik pantai sesuai untuk olahraga Surfing, ekosistem terumbu karang yang baik, kegiatan masyarakat lokal Desa Pangumbahan yakni kegiatan peternakan, pertanian dan perikanan dengan mayoritas sebagai nelayan karena garis pantai yang luas yang menghubungkan langsung ke Samudra Hindia. Namun potensi dan daya tarik yang dimiliki pantai penyu Pangumbahan ini juga perlu adanya penyediaan fasilitas dan akomodasi penunjang kawasan ekowisata sehingga jika ditata akan menjadi kawasan dengan daya tarik lebih. Penulis melakukan beberapa analisis seperti analisis kebijakan, analisis lokasi, analisis tapak, analisis komponen geopark dan ekowisata, analisis best practice, analisis kegiatan wisata, analisis persepsi dan preferensi dan analisis kebutuhan ruang sehingga menghasilkan usulan atau rencana penataan Kawasan Wisata Pantai Pangumbahan Dengan Konsep Ekowisata.
\end{abstract}

Kata Kunci: Ancaman Bencana Tsunami; Ekowisata; Kawasan Wisata Pantai; Konservasi Penyu; Wisata Bahari

\begin{abstract}
Pangumbahan Beach is one of the beaches located in the south of Java Island, precisely in Pangumbahan Village, Ciracap District, Sukabumi Regency, West Java Province. This beach is the area of planning and development of marine tourism within RIPPARDA (Master Plan for Regional Tourism Development) based on District Regulation. Sukabumi No. 10 of 2010 article 49 and has a uniqueness that is not necessarily owned by other beaches such as attraction to release hatchlings, the character of waves that are suitable for surfing, wave character at some beach points suitable for surfing, good coral ecosystems, activities of the local community in Pangumbahan Village namely livestock, agriculture and fisheries with the majority as fishermen because of the extensive coastline that connects directly to the Indian Ocean. However, the potential and attractiveness of Pangumbahan sea turtle beach also needs the provision of facilities and accommodation to support the ecotourism area so that if it is laid out it will become an area with more attraction. The author conducts several analyzes such as policy analysis, location analysis, site analysis, geopark and ecotourism component analysis, best practice analysis, analysis of tourism activities, perception and preference analysis and space requirements analysis to produce a proposal or plan for Pangumbahan Beach Tourism Area with Ecotourism Concept.
\end{abstract}

Keywords: Coastal Tourism Areas; Ecotourism; Marine Tourism; Tsunami Disaster Threats; Turtle Conservation 


\section{PENDAHULUAN}

Indonesia adalah salah satu negara kepulauan terluas yang di dalamnya terdapat beribu ribu pulau sehingga sangat berpotensi dengan sektor pariwisatanya. Pariwisata kini sudah menjadi penggerak untuk meningkatkan perekonomian melalui penyediaan lapangan pekerjaan, devisa negara serta pembangunan infrastruktur pendukung kegiatan pariwisata. Perkembangan sektor pariwisata di Indonesia setiap tahun semakin berkembang pesat dikarenakan dengan keindahan, keunikan dan keberagaman kekayaan alam yang ada di Indonesia.

Salah satu objek wisata di Indonesia yang menjadi daya tarik wisatawan untuk berkunjung adalah objek wisata alam. Wisata alam di Indonesia didukung dengan kekayaan biota laut yang menciptakan berbagai macam objek wisata yang tersebar dari Sabang sampai Merauke. Indonesia juga merupakan negara kepulauan dengan garis pantai terpanjang ketiga di dunia setelah Kanada dan Uni Eropa. Hal tersebut membuat banyak pantai di manfaatkan sebagai wisata bahari sebagai tujuan wisata untuk wisatawan lokal maupun wisatawan mancanegara. Provinsi Jawa barat mempunyai potensi dan daya tarik untuk objek wisata pantai yang biasa dikenal kalangan masyarakat sebagai wisata pantai selatan khususnya di Kabupaten Sukabumi.

Pantai Pangumbahan terletak di Desa Pangumbahan, Kecamatan Ciracap, Kabupaten Sukabumi, Provinsi Jawa Barat. Pantai Pangumbahan merupakan salah satu pantai di Desa Pangumbahan yang dijadikan tujuan wisata dikarenakan pantainya masih sangat bersih dan alami. Pantai Pangumbahan juga memiliki banyak daya tarik wisata seperti tempat penangkaran penyu, olahraga surfing, serta tradisi Hari Nelayan yang masih dirayakan turun temurun oleh masyarakat lokal di sekitar Pantai Pangumbahan.

Namun keindahan Pantai Pangumbahan diperlukan perencanaan penataan yang lebih baik lagi khususnya fasilitas, sarana dan prasarana di sekitar Pantai Pangumbahan yang perlu disediakan dan ditata dengan lebih baik lagi dengan tetap memperhatikan prinsip dan konsep ekowisata. Pantai Pangumbahan jika terus dikembangkan dan ditata dengan baik akan menarik wisatawan lokal maupun wisatawan mancanegara sehingga dapat meningkatkan perekonomian masyarakat sekitar Pantai Pangumbahan dan memberikan edukasi terhadap wisatawan yang datang akan pentingnya menjaga ekosistem alam di Pantai Pangumbahan. Atas dasar tersebut, penulis tertarik untuk melakukan rencana penataan pada pantai ini sehingga meskipun aksesnya cukup jauh, namun tetap didukung dengan pembangunan infrastruktur oleh pemerintah sehingga pengunjung yang sudah datang tetap ingin berkunjung kembali setelah melihat atraksi dan daya tarik serta fasilitas pendukung di Pantai Pangumbahan. Adapun tujuan dari penelitian ini sebagai berikut :

1) Mengetahui potensi wisata dan kebutuhan wisatawan di kawasan wisata Pantai Pangumbahan.

2) Membuat usulan rencana penataan kawasan (masterplan) Pantai Pangumbahan sehingga menjadi nilai tambah untuk wisata Pantai Pangumbahan dan sekitarnya.

\section{KAJIAN LITERATUR}

\section{Ekowisata}

Prinsip pengembangan ekowisata sebagaimana di maksud dalam pasal 2 permendagri No.

33 tahun 2009 tentang pengembangan ekowisata berbasis masyarakat dan konservasi, yakni :

1) Kesesuaian antar jenis dan karakterisitik ekowisata

2) Konservasi, yaitu melindungi, mengawetkan, dan memamfaatkan secara lestari sumberdaya alam yang digunakan untuk ekowisata

3) Ekonomis, yaitu memberikan manfaat untuk masyarakat setempat dan menjadi penggerak pembangunan ekonomi di wilayahnya serta memastikan usaha ekowisata dapat berkelanjutan.

4) Edukasi, yaitu mengandung unsur pendidikan untuk mengubah persepsi seorang agar memiliki kepedulian, tanggung jawab, dan komitmen terhadap pelestarian lingkungan dan budaya. 
5) Memberikan kepuasan dan pengalaman kepada pengunjung.

6) Partisipasi masyarakat, yaitu peran serta masyarakat dalam kegiatan perencanaan, pemanfaatan, dan pengendalian ekowisata dengan menghormati nilai-niali sosialbudaya dan keagamaan masyarakat disekitar kawasan.

7) Menampung kearifan lokal.

\section{Konsep Pengembangan Fasilitas Wisata}

Menurut (Maryani, 2009), suatu lokasi wisata dapat menarik untuk dikunjungi oleh wisatawan harus memenuhi syarat-syarat sebagai berikut :

1) Objek wisata yang berbeda dengan yang dimiliki daerah lain, mempunyai daya tarik khusus dan atraksi yang dapat di jadikan hiburan bagi wisatawan.

2) Ketersediaan berbagai fasilitas yang dapat membuat wisatawan betah tinggal lebih lama di tempat itu.

3) Ketersediaan fasilitas untuk berbelanja (shopping) terutama barang souvenir dan kerajinan rakyat sebagai oleh-oleh untuk dibawa pulang ke tempat asal.

4) Aksesbilitas, yakni bagaimana wisatawan mengunjungi objek wisata tersebut, kendaraan apa yang akan digunakan dan beberapa dan berapa lama tiba ditempat wisata itu.

5) Cara wisatawan akan menetap/tinggal untuk sementara waktu selama ia berlibur di objek wisata itu (ketersediaan akomodasi).

\section{Unsur Objek Wisata}

Menurut (Inskeep, 1991), suatu obyek wisata harus mempunyai 5 unsur penting, yakni :

1) Daya tarik, faktor yang menarik wisatawan untuk mengadakan perjalanan wisata mengunjungi suatu tempat.

2) Prasarana wisata untuk melayani wisatawan selama perjalanan wisata.

3) Sarana wisata untuk melayani kebutuhan wisatawan dalam menikmati perjalanan wisatanya.

4) Infrastruktur untuk mendukung fungsi sarana dan prasarana wisata.

5) Masyarakat, lingkungan, dan budaya

\section{METODE}

Penelitian ini terdapat dua jenis data yakni data primer dan data sekunder, antara lain sebagai berikut :

a. Data Primer

Data primer merupakan data yang didapat langsung dari objek penelitian. Teknik pengumpulan data primer yaitu sebagai berikut:

1) Survei Lapangan

Survey lapangan merupakan metode pengamatan langsung pada objek penelitian yang dilakukan oleh peneliti untuk mendapatkan data yang tidak bisa di dapatkan pada dengan cara sekunder. Survei lapangan ini bertujuan untuk mengetahui kondisi lapangan terkini dari objek yang akan diteliti.

2) Wawancara

Wawancara akan dilakukan dengan pihak terkait yaitu pihak pengelola Geopark Ciletuh Palabuhanratu, Dinas Pariwisata dan Kebudayaan Provinsi Jawa Barat, Dinas Perhubungan Provinsi Jawa Barat, Dinas Pariwisata Kabupaten Sukabumi, Kepala Camat Kecamatan Ciracap, Kepala Desa Ujung Genteng, Pengelola Konservasi Penyu Pangumbahan dan masyarakat sekitar kawasan wisata pantai di Desa Pangumbahan.

3) Kuesioner

Kuesioner dibuat dan disebarkan untuk mengetahui persepsi masyarakat mengenai kondisi eksisting Kawasan wisata pantai di Desa Pangumbahan, serta mengenai konsep yang akan diterapkan. 


\section{b. Data Sekunder}

Data sekunder merupakan data yang didapatkan dari berbagai sumber yang relevan seperti buku, jurnal, dokumen-dokumen pemerintah serta sumber dari internet yang dapat dipertanggung jawabkan. Data sekunder yang diperoleh adalah sebagai berikut:

1) Peraturan kebijakan yang terkait dengan wisata pantai Pangumbahan.

2) Dokumentasi dan data pendukung terkait wisata pantai Pangumbahan.

3) Data makro Kabupaten Sukabumi.

\section{DISKUSI DAN HASIL}

\section{Profil Pantai Pangumbahan}

Pantai Pangumbahan adalah pantai di pesisir Selatan Jawa Barat yang ditetapkan sejak 2006 oleh IUCN (International Union for Conservation of Nature and Natural Resources) sebagai salah satu dari 32 (tiga puluh dua) tapak peneluran utama penyu hijau (Chelonia Mydas) di dunia. Pantai Pangumbahan berlokasi di Desa Pangumbahan, RT. 05, RW. 09, Kecamatan Ciracap, Kabupaten Sukabumi, Provinsi Jawa Barat. Pantai Pangumbahan dibagi menjadi 3 zona yakni zona Inti $(68,48 \mathrm{Ha})$, zona penyangga (42 Ha), zona pelayanan $(29,72 \mathrm{Ha})$. Kawasan penyangga dan kawasan pelayanan adalah kawasan yang dibutuhkan untuk menyangga kawasan inti konservasi dan menjamin berlangsungnya konservasi penyu secara berkelanjutan dimana apabila tidak ada kawasan penyangga dan pelayanan yang ditata dengan baik, diyakini oleh para ahli penyu bahwa penyu di Pangumbahan dapat segera punah/pindah. Lahan di zona penyangga dan zona pelayanan setelah 1945 adalah tanah bekas perkebunan Belanda yang dikuasai oleh negara dan dikelola oleh Yayasan Kepolisian melalui PT Brajatama kini menjadi PT Wira Citespong. Untuk status lahannya adalah setifikat Hak Guna Usaha (HGU) No. U-15 atas nama PT Brajatama (sekarang PT Wira Citespong) dengan masa HGU berakhir pada tahun 2020 sehingga pihak Pemprov Jawa Barat merencanakan melakukan penataan untuk lahan penyangga dan pelayanan konservasi penyu menjadi kawasan pariwisata.

\section{Analisis Tapak}

Penggunaan Lahan

Batasan objek studi dengan luas $71,72 \mathrm{Ha}$ ini terdiri dari beberapa jenis penggunaan lahan. Berikut ini adalah tabel penggunaan lahan:

Tabel 1. Penggunaan Lahan Objek Studi di Pantai Pangumbahan

\begin{tabular}{cccl}
$\begin{array}{c}\text { Penggunaan } \\
\text { Lahan }\end{array}$ & Luas & Presentase & \multicolumn{1}{c}{ Keterangan } \\
\hline $\begin{array}{c}\text { Pesisir } \\
\text { (Pasir })\end{array}$ & $7,57 \mathrm{Ha}$ & $10,56 \%$ & $\begin{array}{l}\text { Bagian pesisir merupakan bagian berpasir pantai yang } \\
\text { langsung berbatasan dengan laut. }\end{array}$ \\
\hline Ladang & $11,78 \mathrm{Ha}$ & $16,43 \%$ & $\begin{array}{l}\text { Bagian ini merupakan ladang yang ditanami oleh warga. } \\
\text { Salah satu tumbuhan yang ditanam adalah kacang } \\
\text { tanah, bawang merah dan cabai. }\end{array}$ \\
\hline $\begin{array}{c}\text { Semak } \\
\text { Belukar }\end{array}$ & $28,27 \mathrm{Ha}$ & $39,47 \%$ & $\begin{array}{l}\text { Bagian ini merupakan semak liar yang terletak di } \\
\text { samping bagian pesisir pantai. Salah satu pohon yang } \\
\text { tumbuh merupakan pohon pandan laut untuk menahan } \\
\text { abrasi serta mengundang naluriah penyu untuk } \\
\text { bertelur. }\end{array}$ \\
\hline Rumput & $4 \mathrm{Ha}$ & $5,57 \%$ & $\begin{array}{l}\text { Bagian ini merupakan lahan kosong yang beralaskan } \\
\text { rumput liar. }\end{array}$ \\
\hline Sawah & $6,1 \mathrm{Ha}$ & $8,43 \%$ & $\begin{array}{l}\text { Bagian sawah ini merupakan salah satu sumber } \\
\text { penghasilan masyarakat lokal dengan menjual hasil } \\
\text { panen padinya. }\end{array}$ \\
\hline Tegalan & $4,14 \mathrm{Ha}$ & $5,78 \%$ & \begin{tabular}{l} 
Tegalan ini berada di sekitar perumahan yang letaknya \\
\hline
\end{tabular} \\
\hline
\end{tabular}




\begin{tabular}{cccl}
\hline $\begin{array}{c}\text { Penggunaan } \\
\text { Lahan }\end{array}$ & Luas & Presentase & \multicolumn{1}{c}{ Keterangan } \\
\hline Wisata & $8,28 \mathrm{Ha}$ & $11,54 \%$ & $\begin{array}{l}\text { terpisah dengan halaman rumah yang digunakan } \\
\text { masyarakat sekitar untuk menanam tumbuhan seperti } \\
\text { pohon kelapa, pepaya dan mangga. }\end{array}$ \\
\hline Perumahan & $1,58 \mathrm{Ha}$ & $2,28 \%$ & $\begin{array}{l}\text { Wisata yang ada terbagi menjadi dua bagian, bagian } \\
\text { pertama merupakan penginapan berupa losmen, } \\
\text { pondok wisata serta warung \& rumah makan seafood di } \\
\text { daerah pesisir pantai. }\end{array}$ \\
\hline Jumlah & $\mathbf{7 1 , 7 2 ~ H a}$ & $\mathbf{1 0 0 \%}$ & $\begin{array}{l}\text { Perumahan yang ada biasanya digunakan sebagai } \\
\text { Homestay untuk wisatawan yang datang. }\end{array}$ \\
\hline
\end{tabular}

Sumber: Penulis, 2019

\section{Fasilitas di Kawasan Wisata Pantai Pangumbahan}

Berikut ini adalah usulan dan rekomendasi terhadap fasilitas pendukung yang ada di kawasan wisata Pantai Pangumbahan berdasarkan kondisi eksisting yang telah dijelaskan di atas:

Tabel 2. Usulan Fasilitas Umum \& Pariwisata Pantai Pangumbahan

\begin{tabular}{cccc}
\hline No & Fasilitas & Kondisi & Ketersediaan \\
\hline 1 & Area Parkir & $\begin{array}{c}\text { Non } \\
\text { Permanen }\end{array}$ & Belum Cukup \\
& & & \\
\hline 2 & Toilet Umum & $\begin{array}{c}\text { Non } \\
\text { Permanen }\end{array}$ & Belum Cukup \\
& & &
\end{tabular}

Perlu dilakukan pembangunan khusus area parkir dengan bidang yang datar sehingga saat musim ramai dikunjungi wisata dapat terorganisir dengan baik dengan penataan dan pengelolaan parkir yang baik.

Permanen tempat bilas/mandi karena wisatawan hanya bisa menggunakan fasilitas toilet yang diberikan oleh masing-masing penginapan maupun rumah makan di sekitar.

\begin{tabular}{cccc}
\hline 3 & Pos Keamanan / & Semi & Belum Cukup \\
& Penjualan Tiket & Permanen & \\
Masuk & & &
\end{tabular}

Perlu dibangun pos kemanan yang permanen dan memadai di sekitar kawasan penyangga dan kawasan pelayan Pantai Pangumbahan sehingga dapat menunjang kenyamanan dan keamanan terhadap pengunjung yang datang.

\begin{tabular}{|c|c|c|c|c|}
\hline 4 & Pondok Wisata & $\begin{array}{c}\text { Non } \\
\text { Permanen }\end{array}$ & Belum Baik & $\begin{array}{l}\text { Pondok wisata di sekitar pesisir Pantai } \\
\text { Pangumbahan perlu penyegaran dan penataan } \\
\text { agar tidak menghalangi pandangan wisatwan } \\
\text { ke pantai/laut. Hal tersebut akan menambah } \\
\text { estetika dan kenyamanan wisatawan yang } \\
\text { datang. }\end{array}$ \\
\hline 5 & Losmen & $\begin{array}{c}\text { Semi } \\
\text { Permanen }\end{array}$ & Belum Baik & $\begin{array}{l}\text { Losmen di sekitar Pantai Pangumbahan perlu } \\
\text { dibangun menggunakan material ramah } \\
\text { lingkungan seperti sumber daya yang dapat } \\
\text { diperbaharui (kayu kelapa, kayu bekas, } \\
\text { bamboo, kayu tanaman buah-buahan seperti } \\
\text { pohon manga dll) sehingga tidak merusak lahan } \\
\text { di sekitar pantai dan memberikan kesan yang } \\
\text { lebih natural dan ramah lingkungan. }\end{array}$ \\
\hline 6 & Warung & $\begin{array}{c}\text { Non } \\
\text { Permanen }\end{array}$ & Belum Baik & $\begin{array}{l}\text { Warung eksisting perlu dilakukan penataan } \\
\text { kembali dan dibangun dengan lebih baik } \\
\text { sehingga dapat memberikan pelayanan yang } \\
\text { baik terhadap wisatawan. }\end{array}$ \\
\hline 7 & Rumah makan & Semi & Belum Baik & Rumah makan yang tersedia masih kurang dan \\
\hline
\end{tabular}




\begin{tabular}{ccccc}
\hline No & Fasilitas & Kondisi & Ketersediaan & \multicolumn{2}{c}{ Usulan } \\
\hline & & Permanen & perlu ada penambahan tempat makan dan \\
& & & $\begin{array}{l}\text { variasi menu makanan untuk melayani } \\
\text { wisatawan yang datang. }\end{array}$ \\
\hline 6 & Pos Pengawas & Semi & Belum Cukup & Pos pengawas/jaga belum terdapat di sekitar \\
& (Menara & Permanen & & kawasan penyangga dan kawasan pelayanan \\
& pemantau) & & Pantai Pangumbahan sehingga perlu ada \\
& & & penambahan di beberapa titik di sepanjang \\
& & & garis Pantai Pangumbahan. \\
\hline
\end{tabular}

Sumber: Penulis, 2019

\section{Prasarana di Kawasan Wisata Pantai Pangumbahan}

Berikut ini adalah usulan dan rekomendasi prasarana di Kawasan Wisata Pantai Pangumbahan berdasarkan kondisi eksisting yang telah dijelaskan di atas:

Tabel 3. Usulan Prasarana Pantai Pangumbahan

\begin{tabular}{|c|c|c|c|}
\hline No & Prasarana & Ketersediaan & Usulan \\
\hline 1 & Jaringan Jalan & Belum Memadai & $\begin{array}{l}\text { Perlu dilakukan peningkatan berupa pelebaran dan } \\
\text { pengaspalan beberapa titik jalan yang masih berlubang } \\
\text { menuju maupun di area Pantai Pangumbahan sehingga } \\
\text { lebih memudahkan sirkulasi pengunjung. }\end{array}$ \\
\hline 2 & $\begin{array}{c}\text { Listrik \& } \\
\text { Penerangan }\end{array}$ & Cukup Memadai & $\begin{array}{l}\text { Listrik sudah sampai ke semua akomodasi di sekitar areal } \\
\text { wisata Pantai Pangumbahan. Sedangkan untuk } \\
\text { penerangan harus disediakan di tempat yang terdapat } \\
\text { kegiatan namun tepat tidak berlebihan sehingga tidak } \\
\text { menggangu penyu yang ingin mendarat untuk bertelur di } \\
\text { sekitar pesisir Pantai Pangumbahan. Untuk kedepannya } \\
\text { bisa menggunakan teknologi sel surya untuk penerangan } \\
\text { yang ramah lingkungan. }\end{array}$ \\
\hline 3 & Air Bersih & Cukup Memadai & $\begin{array}{l}\text { Untuk kedepannya dapat memanfaatkan air tanah } \\
\text { maupun air sungai secara terkendali dan proposional agar } \\
\text { tidak terjadi hal-hal negatif dikemudian hari }\end{array}$ \\
\hline 4 & Tempat Sampah & Belum Memadai & $\begin{array}{l}\text { Perlu dibuat rencana pembangunan TPS untuk } \\
\text { pengangkutan dan pengelolaan sampah serta dengan } \\
\text { mensosialisasikan 3R (reduce, reuse, recycle) kepada } \\
\text { masyarakat maupun wisatawan sehingga dapat menjaga } \\
\text { kebersihan Pantai Pangumbahan. }\end{array}$ \\
\hline 5 & $\begin{array}{c}\text { Jaringan } \\
\text { Komunikasi }\end{array}$ & Sudah Memadai & $\begin{array}{l}\text { Jaringan komunikasi di Kawasan Wisata Pantai } \\
\text { Pangumbahan sudah cukup baik. Untuk kedepannya, } \\
\text { dapat di kembangkan dan ditambahkan fasilitas seperti } \\
\text { Free Wifi untuk menunjang kegiatan wisatawan di sekitar } \\
\text { Pantai Pangumbahan. }\end{array}$ \\
\hline
\end{tabular}

Sumber: Penulis, 2019

\section{Garis Sempadan Pantai Kawasan Wisata Pantai Pangumbahan}

Berdasarkan Peraturan Menteri Kelautan dan Perikanan RI NO. 21 tahun 2018 Tentang Tata Cara Penghitungan Batas Sempadan Pantai, sempadan pantai merupakan daratan sepanjang tepian pantai, yang lebarnya proporsional dengan bentuk dan kondisi fisik pantai, minimal 100 meter dari titik pasang tertinggi ke arah darat.

Dapat dilihat bahwa di kondisi eksisting di dalam deliniasi objek studi masih banyak terdapat bangunan yang berada di dalam area sempadan pantai sehingga untuk kedepannya, bangunan yang berada di dalam area sempadan pantai akan direlokasi ke area efektif yang memang secara peraturan dapat dibangun dan dikembangkan sehingga dapat melindungi dan menjaga kelestarian fungsi ekosistem dan segenap sumber daya yang berada di wilayah pesisir 
serta mengurangi dampak ancaman terhadap bencana alam. Berikut merupakan luasan efektif masing-masing zona :

Tabel 4. Luasan Efektif Zona Penyangga dan Zona Pelayanan

\begin{tabular}{lcc}
\hline \multirow{2}{*}{ Keterangan } & \multicolumn{2}{c}{ Pembagian Zona } \\
\cline { 2 - 3 } & Zona Penyangga & Zona Pelayanan \\
\hline Luas Total deliniasi & $42 \mathrm{Ha}$ & $29,72 \mathrm{Ha}$ \\
\hline Luas Area Sempadan & $17,03 \mathrm{Ha}$ & $11,6 \mathrm{Ha}$ \\
\hline Sisa Luas Efektif di dalam deliniasi & $24,97 \mathrm{Ha}$ & $18,12 \mathrm{Ha}$ \\
\hline Sumber: Penulis, 2019 & &
\end{tabular}

\section{Daerah Rawan Bencana Kawasan Wisata Pantai Pangumbahan}

Berdasarkan data dari BMKG (Badan Meteorologi, Klimatologi dan Geofisikia), daerah pulau Jawa khususnya area pantai selatan pulau Jawa Barat pernah mengalami bencana tsunami. Berikut merupakan data bencana tsunami di daerah pantai selatan area pulau Jawa:

Tabel 5. Bencana Tsunami yang pernah terjadi di daerah Selatan Laut Jawa

\begin{tabular}{|c|c|c|c|c|c|c|}
\hline \multirow{2}{*}{ No. } & \multicolumn{2}{|c|}{ Waktu Kejadian } & \multirow{2}{*}{$\begin{array}{l}\text { Mag. } \\
\text { Gempa }\end{array}$} & \multirow{2}{*}{ Sumber Tsunami } & \multirow{2}{*}{ Ketinggian } & \multirow{2}{*}{ Refrensi } \\
\hline & Tanggal & Pukul & & & & \\
\hline 1 & 2 Sep 09 & 7:55:00 & 7,3 & Tasikmalaya, Jawa Barat & - & $\begin{array}{c}\text { BMKG, } \\
\text { Bakosurtanal }\end{array}$ \\
\hline 2 & 17 Juli 06 & $8: 19: 22$ & 6,8 & Pangandaran, Jawa Barat & $3-8 m$ & $\begin{array}{c}\text { BMKG, } \\
\text { Bakosurtanal }\end{array}$ \\
\hline
\end{tabular}

Sumber: Penulis, 2019

Dapat dilihat bahwa di kontur daratan eksisting di dalam deliniasi objek studi masih di range ketinggian 0 meter hingga 3,25 meter dimana area tersebut merupakan area rawan bencana tsunami jika melihat ketinggian tsunami yang pernah terjadi di pantai selatan khususnya Pantai Pangandaran sehingga untuk kedepannya direncanakan untuk membuat bukit evakuasi dengan ketinggian minimal 6 meter sebagai pertolongan utama kepada pengunjung yang datang untuk evakuasi sementara. Berikut merupakan perhitungan ketinggian kontur darat di dalam Kawasan Wisata Pantai Pangumbahan:

Tabel 6. Ketinggian Kontur Darat dan Tsunami Yang Terjadi

\begin{tabular}{|c|c|c|}
\hline No. & Keterangan & Ketinggian \\
\hline 1 & Kontur Darat Eksisting & 2 meter \\
\hline 2 & Ketinggian Tsunami di Pangandaran & 8 meter \\
\hline 3 & Ketinggian Minimal Rencana Bukit Evakuasi & 6 meter \\
\hline
\end{tabular}

\section{Status Kepemilikan Tanah di Kawasan Wisata Pantai Pangumbahan}

Berdasarkan data dari BPN (Badan Pertanahan Nasional), status tanah di dalam deliniasi objek studi terdiri dari 2 kategori yakni hak milik dan hak guna usaha. Berikut merupakan tabel persentase berdasarkan status kepemilikan tanah di Kawasan Wisata Pantai Pangumbahan:

Tabel 7. Persentase Kepemilikan Tanah

\begin{tabular}{|c|c|c|c|}
\hline No. & Status Kepemilikan Tanah & Luas (Ha) & Persentase \\
\hline 1 & Hak Milik & 1,58 & $2,28 \%$ \\
\hline 2 & Hak Guna Usaha & 70,14 & $97,72 \%$ \\
\hline & Total & 71,72 & $100 \%$ \\
\hline
\end{tabular}

Sumber: Penulis, 2019 
Untuk rencana kedepannya maka lahan hak milik sebesar 1,58 Ha tersebut akan dipertahankan sedangkan untuk hak guna usaha sebesar 70,14 Ha akan dilakukan penataan sesuai dengan regulasi dan pasar. Berikut merupakan SWOT (strenght, weakness, opportunities, threats) dari analisis sebelumnya:

Tabel 8. Hasil SWOT

\begin{tabular}{|c|c|c|}
\hline \multirow{8}{*}{$\begin{array}{l}\text { Faktor } \\
\text { Internal }\end{array}$} & Strenght - S & Weaknesses - W \\
\hline & Pemandangan yang indah & $\begin{array}{l}\text { Kurang kesadaran masyarakat akan } \\
\text { potensi pariwisata }\end{array}$ \\
\hline & Banyak atraksi wisata yang dapat dilakukan & $\begin{array}{l}\text { Sarana dan prasarana serta fasilitas } \\
\text { kurang memadai }\end{array}$ \\
\hline & $\begin{array}{l}\text { Memiliki ciri khas / keunikan dibandingkan } \\
\text { objek wisata lain berupa konservasi penyu }\end{array}$ & Merupakan area rawan bencana tsunami \\
\hline & $\begin{array}{l}\text { Dari segi area lahan yang bisa dikembangkan } \\
\text { untuk kegiatan wisata masih relatif luas }\end{array}$ & $\begin{array}{l}\text { Kurangnya informasi dan promosi } \\
\text { terhadap keberadaan obyek dan daya } \\
\text { tarik wisata baik oleh pengelola wisata } \\
\text { maupun pemerintah daerah/dinas } \\
\text { pariwisata daerah }\end{array}$ \\
\hline & $\begin{array}{l}\text { Didukung oleh potensi budaya (kesenian) } \\
\text { dan produk mata pencaharian masyarakat } \\
\text { lokal }\end{array}$ & Waktu tempuh perjalanan cukup lama \\
\hline & $\begin{array}{l}\text { Memberikan pengalaman wisata yang } \\
\text { berbeda dari wisata alam pada umumnya }\end{array}$ & $\begin{array}{l}\text { Kurangnya pemberdayaan masyarakat } \\
\text { lokal untuk ekonomi sekitar }\end{array}$ \\
\hline & $\begin{array}{l}\text { Pemerintah mempunyai hak penuh atas } \\
\text { lahan saat penyerahan HGU } 2020\end{array}$ & $\begin{array}{l}\text { Masih banyak bangunan eksisting tidak } \\
\text { tertata di areal sempadan pantai }\end{array}$ \\
\hline \multirow{9}{*}{$\begin{array}{l}\text { Faktor } \\
\text { Eksternal }\end{array}$} & Opportunitties - 0 & Threats - T \\
\hline & $\begin{array}{l}\text { Masih dimungkinkan membentuk lembaga } \\
\text { khusus pengelola (Badan Pengelola) } \\
\text { kawasan dan fasilitasnya dengan } \\
\text { memberdayakan masyarakat setempat. }\end{array}$ & $\begin{array}{l}\text { Sudah banyak objek wisata di luar } \\
\text { Kabupaten Sukabumi yang berkembang } \\
\text { lebih dahulu seperti Tangkuban perahu } \\
\text { (kab. Bandung) dan Ciater (Kab. Subang) } \\
\text { dengan kelengkapan fasilitas penunjang } \\
\text { yang memadai. }\end{array}$ \\
\hline & $\begin{array}{l}\text { Berada dalam kawasan Geopark Ciletuh } \\
\text { Palabuhanratu yang sudah diakui UNESCO }\end{array}$ & $\begin{array}{lcc}\text { Terdapat konflik lahan untuk } \\
\text { pengembangan Bandara Citarate }\end{array}$ \\
\hline & $\begin{array}{l}\text { Potensi daya tarik wisata pantai dan bahari } \\
\text { masih bisa dikembangkan secara luas } \\
\text { berbasis lingkungan dan budaya setempat }\end{array}$ & \\
\hline & $\begin{array}{l}\text { Dukungan Stakeholder untuk memajukan } \\
\text { wisata Pantai Pangumbahan }\end{array}$ & \\
\hline & $\begin{array}{l}\text { Adanya perda dari Pemerintah Kabupaten } \\
\text { Sukabumi untuk mengembangkan obyek } \\
\text { wisata Ujung Genteng-Pangumbahan }\end{array}$ & \\
\hline & $\begin{array}{l}\text { Menempatkan obyek wisata Pantai } \\
\text { Pangumbahan untuk menjadi salah satu } \\
\text { paket wisata yang di tawarkan oleh Geopark } \\
\text { Ciletuh }\end{array}$ & \\
\hline & $\begin{array}{l}\text { Terdapat rencana pembangunan jalan Tol } \\
\text { Bocimi yang akan menunjang akses ke lokasi } \\
\text { wisata }\end{array}$ & \\
\hline & $\begin{array}{l}\text { Terdapat rencana pembangunan Bandara } \\
\text { Citarate yang akan menunjang akses ke } \\
\text { lokasi wisata }\end{array}$ & \\
\hline
\end{tabular}




\section{Analisis Best Practice}

Objek studi yang dipilih untuk dijadikan benchmarking adalah Pantai Tiga Warna dan Pantai Konservasi Penyu Pariaman. Berikut ini merupakan kunci sukses dari kedua objek benchmarking:

1) Konservasi : Fasilitas yang dibangun harus ramah lingkungan dan masyarakat lokal di arahkan untuk berpartisipasi dalam kegiatan wisata sehingga dapat meningkatkan perekonomian sekitar.

2) Partisipasi Masyarakat : Masyarakat diberi pelatihan untuk dapat menerima wisatawan dengan ramah \& baik serta membantu untuk penyediaan jasa maupun akomodasi penginapan.

3) Edukasi :

a. Masyarakat diberi pengetahuan/informasi seputar objek wisata sehingga wisatawan yang datang akan menghargai alam sekitar objek wisata.

b. Kesadaran masyarakat untuk kegiatan konservasi di kawasan pantai, sehingga mampu memberikan dorongan wisatawan untuk ikut dalam melestarikan alam.

c. Wisatawan dapat menghargai kearifan lokal yang ada di sekitar kawasan wisata pantai Pangumbahan.

4) Ekonomis :

a. Akomodasi yang disediakan menggunakan jasa dari masyarakat lokal.

b. Mengutamakan pegawai dari masyarakat lokal.

c. Terdapat regulasi yang mengatur standar kelayakan homestay sesuai dengan kondisi lokasi wisata.

5) Menampung kearifan lokal : Mempromosikan dan memberikan kontribusi dalam usaha peningkatan dan konservasi budaya lokal sehingga budaya setempat bisa dijadikan atraksi dan produk wisata.

Berikut merupakan kegiatan dan fasilitas wisata yang dapat di tambahkan menurut benchmarking adalah:

Tabel 9. Kegiatan dan Fasilitas Wisata yang dapat diterapkan

\begin{tabular}{cll}
\hline No & \multicolumn{1}{c}{ Kegiatan Wisata } & \multicolumn{1}{c}{ Fasilitas Wisata } \\
\hline 1 & Camping & Toilet Umum \\
\hline 2 & Menanam Bakau & Parkir kendaraan \\
\hline 3 & Rehabilitasi \& Transplantasi Terumbu Karang & Pusat Informasi \\
\hline 4 & Telusur Pantai & Agent / pemandu wisata \\
\hline 5 & Mengamati Penyu & Tempat penyewaan fasilitas wisata \\
\hline 6 & & Laboratorium \\
\hline 7 & Homestay \\
\hline 8 & Menara Pemantau \\
\hline 9 & Petunjuk Arah dan papan pengetahuan \\
\hline 10 & Gazebo \\
\hline 11 & Toko Souvenir \\
\hline 12 & ATM \\
\hline
\end{tabular}

Sumber: Penulis, 2019

\section{Analisis Persepsi dan Preferensi}

Dari analisis persepsi, analisis hubungan dan kebutuhan, serta preferensi pengunjung diatas maka penulis memiliki kesimpulan tentang fasilitas pendukung dan prasarana di kawasan wisata Pantai Pangumbahan sebagai berikut :

a. Pengembangan prasarana eksisting adalah prasarana jalan, listrik dan penerangan, persampahan, air bersih dan mempertahankan prasarana telekomunikasi yang eksistingnya sudah cukup baik 
b. Prioritas pengembangan fasilitas pendukung adalah toilet umum dan tempat bilas, penginapan, area parkir, menara pemantau, rumah makan dan warung serta mempertahankan pos keamanan/tiket masuk yang kondisi eksistingnya sudah cukup baik

c. Rencana penambahan fasilitas pendukung seperti fasilitas wisata di darat (tenda, sepeda, outbond, lapangan outdoor), fasilitas wisata di air (ruang ganti, alat selancar, alat memancing, dII), jogging track, pusat plaza, gazebo, pusat informasi, laboratorium, ruang karantina penyu, balai pertunjukan seni budaya dan ATM serta penyediaan bibit bakau, penyediaan media transplantasi terumbu karang untuk menambah kegiatan yang mengedepankan kelestarian alam sekitar kawasan wisata Pantai Pangumbahan.

\section{Analisis Kebutuhan Ruang}

Berdasarkan data pengunjung yang diperoleh dari Dinas parwisata dan kebudayaan provinsi Jawa Barat, diketahui bahwa pertumbuhan pengunjung di kawasan wisata pantai Pangumbahan setiap tahunnya mengalami peningkatan. Berikut merupakan proyeksi pengunjung Pantai Pangumbahan dalam 10 tahun kedepan dengan dihitung menggunakan metode geometrik :

Tabel 10. Proyeksi Pengunjung Pantai Pangumbahan

\begin{tabular}{cc}
\hline Tahun & Jumlah Pengunjung \\
\hline 2013 & 28.335 \\
\hline 2014 & 28.943 \\
\hline 2015 & 33.629 \\
\hline 2016 & 37.913 \\
\hline 2017 & 46.304 \\
\hline 2018 & 52.353 \\
\hline 2019 & 59.192 \\
\hline 2020 & 66.925 \\
\hline 2021 & 75.668 \\
\hline 2022 & 85.553 \\
\hline 2023 & 96.730 \\
\hline 2024 & 109.367 \\
\hline 2025 & 123.654 \\
\hline 2026 & 139.808 \\
\hline 2027 & 158.073 \\
\hline Sumber: Penulis, 2019
\end{tabular}

Dalam melakukan penataan diperlukan pembagian zona perencanaan. Untuk pembagian zona perencanaan di kawasan wisata Pantai Pangumbahan dibagi menjadi 3 zona, yakni :

1) Zona Sempadan Pantai

Zona garis sempadan pantai ini mempunyai luas 28,63 Ha yang berada di kawasan penyangga dan kawasan pelayanan di area perencanaan yang berfungsi menjadi zona kelestarian ekosistem dan vegetasi alami pantai. Di zona sempadan pantai ini tidak akan dibangun bangunan permanen.

2) Zona 1 (Zona Penyangga)

Zona 1 pada kawasan wisata Pantai Pangumbahan merupakan zona kegiatan utama wisata dengan luas 24,97 Ha. Berdasarkan Rencana Induk Pengembangan Pariwisata (RIPPDA) Kabupaten Sukabumi Tahun 2007, zona ini memiliki fungsi kawasan ekowisata dengan fasilitas yang dikembangkan berupa laboratorium serta kegiatan-kegiatan wisata yang mengedepankan kelestarian alam. 
3) Zona 2 (Zona Pelayanan)

Zona 2 pada kawasan wisata Pantai Pangumbahan merupakan zona pelayanan dengan luas 18,12 Ha. Berdasarkan Rencana Induk Pengembangan Pariwisata Daerah (RIPPDA) Kabupaten Sukabumi Tahun 2007, zona pelayanan ini memiliki fungsi pengembangan sarana pariwisata. zona pelayanan ini akan direncanakan untuk zona penyediaan akomodasi untuk wisatawan serta sarana dan prasarana pendukung kegiatan wisata di sekitar Pantai Pangumbahan.

Dalam rencana penataan ini, penulis telah menghitung estimasi kebutuhan ruang untuk rencana pengembangan yang terbagi pada zona sempadan pantai, zona 1 dan zona 2 . Berikut merupakan kebutuhan ruang untuk masing-masing zona:

Tabel 11. Kebutuhan Ruang Zona sempadan pantai $(28,63 \mathrm{Ha})$

\begin{tabular}{lcccc}
\hline \multicolumn{1}{c}{ Fasilitas } & Luas (m2) & Luas (Ha) & Persentase & Sumber \\
\hline Menara Pemantau & 180 & 0.018 & 0.062871114 & Permenpar \\
\hline Gazebo & 380 & 0.038 & 0.132634765 & NAD,2002 \\
\hline Wilayah Pesisir & 69600 & 6.960 & $\mathbf{2 4 . 3 1 0 1 6 4 1 6}$ & Eksisting \\
\hline Luas Total Lahan & & $\mathbf{7 . 0 1 6}$ Ha dari $\mathbf{2 8 , 6 3 ~ H a}$ & \\
\hline Persentase & & $\mathbf{2 4 . 5 1 \%}$ & \\
\hline
\end{tabular}

Sumber: Penulis, 2019

Tabel 12. Kebutuhan Ruang Zona $1(24,97 \mathrm{Ha})$

\begin{tabular}{|c|c|c|c|c|}
\hline Fasilitas & Luas (m2) & Luas (Ha) & Persentase & Sumber \\
\hline Hunian untuk Homestay & 15800 & 1.580 & 7.94 & Eksisting (status tanah) \\
\hline $\begin{array}{l}\text { Lapangan } \\
\text { Bermain/Outbond }\end{array}$ & 1300 & 0.130 & 0.65 & SNI \\
\hline $\begin{array}{l}\text { Ruang Karantina Penyu dan } \\
\text { Kantor Pengelola }\end{array}$ & 12800 & 1.280 & 6.43 & Asumsi menikuti Zona Inti \\
\hline Laboratorium & 5460 & 0.546 & 2.74 & NAD,2002 \\
\hline $\begin{array}{l}\text { Penyewaan Alat Wisata } \\
\text { Konservasi }\end{array}$ & 4320 & 0.432 & 2.17 & Permenpar \\
\hline Penyewaan Alat Wisata Air & 4800 & 0.480 & 2.41 & Permenpar \\
\hline $\begin{array}{l}\text { Pusat Informasi dan Tour } \\
\text { Agent }\end{array}$ & 128 & 0.013 & 0.06 & Permenpar \\
\hline Balai Seni Budaya & 1800 & 0.180 & 0.90 & Permenpar \\
\hline Lapangan Outdoor & 5800 & 0.580 & 2.91 & NAD,2002 \\
\hline Parkir Kendaraan & 10200 & 1.020 & 5.12 & Permenpar \\
\hline Penyewaan sepeda & 4621 & 0.462 & 2.32 & NAD,2002 \\
\hline Toko Souvenir & 2000 & 0.200 & 1.00 & Permenpar \\
\hline Pusat Kuliner & 7400 & 0.740 & 3.72 & SNI \\
\hline Toilet dan Ruang Bilas & 108 & 0.011 & 0.05 & NAD,2002 \\
\hline Musholla & 585 & 0.059 & 0.29 & SNI \\
\hline ATM & 18 & 0.002 & 0.01 & NAD,2002 \\
\hline Pos Keamanan & 9 & 0.001 & 0.00 & NAD, 2002 \\
\hline Klinik & 108 & 0.011 & 0.05 & SNI \\
\hline Bukit Evakuasi & 3200.00 & 0.320 & 1.61 & NAD,2002 dan Potensi Lahan \\
\hline Total Kebutuhan Lahan & \multicolumn{4}{|c|}{$8,05 \mathrm{Ha}$ dari $24,97 \mathrm{Ha}$} \\
\hline Persentase & \multicolumn{4}{|c|}{$32,22 \%$} \\
\hline
\end{tabular}

Sumber: Penulis, 2019 
Tabel 13. Kebutuhan Ruang Zona $2(18,12 \mathrm{Ha})$

\begin{tabular}{|c|c|c|c|c|}
\hline Fasilitas & Luas (m2) & Luas (Ha) & Persentase & Sumber \\
\hline Cottage Tipe Standart (2 lantai) & 15058.56 & 1.506 & 8.31 & Permenpar \\
\hline Cottage Tipe Family (2 lantai) & 14463.36 & 1.446 & 7.98 & Permenpar \\
\hline Relokasi Wisata & 82800 & 8.280 & 45.70 & Relokasi \\
\hline TIC & 77.72 & 0.008 & 0.04 & Permenpar \\
\hline Pos Keamanan & 9 & 0.001 & 0.00 & NAD,2002 \\
\hline Luas Total Lahan & \multicolumn{4}{|c|}{ 11.241 Ha dari $18,12 \mathrm{Ha}$} \\
\hline Persentase & \multicolumn{4}{|c|}{$62.04 \%$} \\
\hline
\end{tabular}

Sumber: Penulis, 2019

Total kebutuhan ruang untuk seluruh fasilitas penunjang yang direncanakan tersebut adalah $26,307 \mathrm{Ha}$ atau $36 \%$ dari total luas keseluruhan tapak $(71,72 \mathrm{Ha})$. Untuk lahan yang masih kosong diperuntukan untuk ruang terbuka hijau dan lahan untuk perencanaan pada masa yang akan datang sehingga tetap dapat mempertahankan kelestarian alam kawasan Pantai Pangumbahan.

\section{Konsep Dan Rencana (Ekowisata)}

Tabel 14. Konsep Berdasarkan Kriteria Ekowisata

\begin{tabular}{|c|c|c|c|}
\hline No & Prinsip Dasar & Kriteria & Konsep \\
\hline \multirow{5}{*}{1} & \multirow{5}{*}{ Konservasi } & $\begin{array}{l}\text { Tingkat kunjungan dan kegiatan } \\
\text { wisatawan pada sebuah daerah tujuan } \\
\text { ekowisata dikelola sesuai dengan } \\
\text { batas-batas yang dapat diterima baik } \\
\text { dari segi alam maupun sosial-budaya }\end{array}$ & $\begin{array}{l}\text { Meningkatkan kualitas dari elemen } \\
\text { yang berhubungan dengan pariwisata } \\
\text { seperti kesehatan, taraf hidup, nilai } \\
\text { ekonomi, kualitas lingkungan (ramah } \\
\text { lingkungan) }\end{array}$ \\
\hline & & $\begin{array}{l}\text { Menggunakan teknologi ramah } \\
\text { lingkungan (listrik tenaga surya, } \\
\text { mikrohidro, biogas, dll.) }\end{array}$ & $\begin{array}{l}\text { Mengedepankan konservasi air, energy } \\
\text { dan pengurangan bahan kimia } \\
\text { sehingga mengurangi dampak negatif } \\
\text { terhadap alam dan eksplorasi } \\
\text { berlebihan terhadap sumber daya }\end{array}$ \\
\hline & & \begin{tabular}{l}
\multicolumn{3}{l}{ Terdapat "ecotourism conservancies" } \\
atau kawasan ekowisata sebagai \\
kawasan dengan peruntukan khusus \\
yang pengelolaannya diberikan kepada \\
organisasi masyarakat yang \\
berkompeten
\end{tabular} & $\begin{array}{l}\text { Meyediakan kegiatan rehabilitasi } \\
\text { terumbu dan menanam bakau dengan } \\
\text { melibatkan POKMASWAS }\end{array}$ \\
\hline & & $\begin{array}{l}\text { Fasilitas pendukung yang dibangun } \\
\text { tidak merusak atau didirikan pada } \\
\text { ekosistem yang sangat unik dan rentan }\end{array}$ & $\begin{array}{l}\text { Membangun sesuai dengan peraturan } \\
\text { sesuai fungsi zonanya masing-masing } \\
\text { dan menggunakan material yang } \\
\text { ramah lingkungan }\end{array}$ \\
\hline & & $\begin{array}{l}\text { Kegiatan ekowisata telah } \\
\text { memperhitungkan tingkat } \\
\text { pemanfaatan ruang dan kualitas daya } \\
\text { dukung lingkungan kawasan tujuan } \\
\text { melalui pelaksanaan sistem zonasi dan } \\
\text { pengaturan waktu kunjungan }\end{array}$ & $\begin{array}{l}\text { Membatasi jumlah pengunjung dengan } \\
\text { strategi pendaftaran via internet dan } \\
\text { mendata barang wisatawan yang } \\
\text { berpotensi menjadi sampah dan } \\
\text { dikenakan denda jika melanggar }\end{array}$ \\
\hline \multirow[b]{2}{*}{2} & \multirow{2}{*}{$\begin{array}{l}\text { Partisipasi } \\
\text { Masyarakat }\end{array}$} & $\begin{array}{l}\text { Kemitraan antara masyarakat dengan } \\
\text { Tour Operator untuk memasarkan dan } \\
\text { mempromosikan produk ekowisata }\end{array}$ & $\begin{array}{l}\text { Menyediakan pusat souvenir dengan } \\
\text { menjual produk yang berasal dari } \\
\text { bahan/material lokal }\end{array}$ \\
\hline & & $\begin{array}{l}\text { Adanya pembagian adil dalam } \\
\text { pendapatan dari jasa kegiatan wisata } \\
\text { di masyarakat }\end{array}$ & $\begin{array}{l}\text { masyarakat yang berkontribusi } \\
\text { mendapat kompensasi dan } \\
\text { keuntungan yang sama (tip, tunjangan, } \\
\text { asuransi, bonus, dll) }\end{array}$ \\
\hline
\end{tabular}




\begin{tabular}{|c|c|c|c|}
\hline & & $\begin{array}{l}\text { Organisasi masyarakat membuat } \\
\text { panduan dan aturan untuk turis }\end{array}$ & $\begin{array}{l}\text { Memberikan peraturan berupa } \\
\text { batasan yang wisatawan dapat lakukan } \\
\text { sehingga menjadi acuan wisatawan } \\
\text { dapat mengikuti kegiatan wisata }\end{array}$ \\
\hline \multirow{3}{*}{3} & \multirow{3}{*}{ Ekonomis } & $\begin{array}{l}\text { Terdapat regulasi yang mengatur } \\
\text { standar kelayakan homestay sesuai } \\
\text { dengan kondisi lokasi wisata }\end{array}$ & $\begin{array}{l}\text { Mengedepankan keamanan, } \\
\text { kebersihan dan kenyaman serta } \\
\text { pelayanan yang efisien \& profesional } \\
\text { untuk wisatawan yang menggunakan } \\
\text { jasa Homestay dan menghindari } \\
\text { perang harga }\end{array}$ \\
\hline & & $\begin{array}{l}\text { Ekowisata dan tour operator turut } \\
\text { mendorong peningkatan pengetahuan } \\
\text { dan keterampilan serta perilaku bagi } \\
\text { para pelaku ekowisata terutama } \\
\text { masyarakat }\end{array}$ & $\begin{array}{l}\text { Mengadakan program pelatihan } \\
\text { kepada masyarakat lokal secara } \\
\text { berkala sehingga jasa-nya dapat } \\
\text { digunakan }\end{array}$ \\
\hline & & $\begin{array}{l}\text { Mendorong adanya prosedur } \\
\text { sertifikasi pemandu sesuai dengan } \\
\text { kondisi lokasi wisata }\end{array}$ & $\begin{array}{l}\text { Menyediakan pemandu lokal yang } \\
\text { sudah diberi pelatihan sesuai dengan } \\
\text { bidangnya sehingga mempertahankan } \\
\text { profesionalisme kerja dan menambah } \\
\text { pengetahuan }\end{array}$ \\
\hline \multirow{3}{*}{4} & \multirow{3}{*}{ Edukasi } & $\begin{array}{l}\text { Masyarakat mendukung dan } \\
\text { mengembangkan upaya konservasi }\end{array}$ & \multirow{3}{*}{$\begin{array}{l}\text { Mengedukasi pengunjung lebih lagi } \\
\text { akan pentingnya keberlangsungan } \\
\text { lingkungan melalui kegiatan wisata } \\
\text { menanam bakau dan rehabilitasi } \\
\text { terumbu karang dengan keterlibatan } \\
\text { masyarakat lokal sebagai penyedia jasa }\end{array}$} \\
\hline & & $\begin{array}{l}\text { Kesadaran masyarakat dan perilaku } \\
\text { masyarakat tentang perlunya upaya } \\
\text { konservasi sumber daya alam hayati } \\
\text { dan ekosistemnya }\end{array}$ & \\
\hline & & $\begin{array}{l}\text { Skema dimana tamu secara sukarela } \\
\text { terlibat dalam kegiatan konservasi dan } \\
\text { pengelolaan kawasan ekowisata } \\
\text { selama kunjungannya } \\
\text { volunteer). }\end{array}$ & \\
\hline \multirow{3}{*}{5} & \multirow{3}{*}{$\begin{array}{l}\text { Menampung } \\
\text { Kearifan } \\
\text { Lokal }\end{array}$} & $\begin{array}{l}\text { Rancangan fasilitas umum sesuai } \\
\text { tradisi lokal, dan masyarakat lokal } \\
\text { terlibat dalam proses perencanaan dan } \\
\text { pembangunan }\end{array}$ & $\begin{array}{l}\text { Rancangannya menggunakan material } \\
\text { lokal yang dapat diperbaharui dengan } \\
\text { menggunakan arsitektur lokal sehingga } \\
\text { mengurangi dampak negatif dan tidak } \\
\text { merusak lingkungan }\end{array}$ \\
\hline & & $\begin{array}{l}\text { Mengembangkan paket-paket wisata } \\
\text { yang mengedepankan budaya, seni } \\
\text { dan tradisi lokal }\end{array}$ & \multirow{2}{*}{$\begin{array}{l}\text { Membangun balai seni budaya sebagai } \\
\text { wadah masyarakat lokal mengemas } \\
\text { kegiatan wisata dengan kreatif } \\
\text { sehingga wisatawan yang datang dapat } \\
\text { pengalaman yang mengesankan dan } \\
\text { menghargai budaya lokal }\end{array}$} \\
\hline & & $\begin{array}{l}\text { Kegiatan sehari-hari dimasukkan ke } \\
\text { dalam atraksi lokal untuk } \\
\text { memperkenalkan wisatawan pada cara } \\
\text { hidup masyarakat dan mengajak } \\
\text { mereka menghargai pengetahuan dan } \\
\text { kearifan lokal }\end{array}$ & \\
\hline
\end{tabular}


Tabel 15. Rencana Penataan Berdasarkan Pembagian Zona

\begin{tabular}{|c|c|c|}
\hline Zona & Fasilitas & Prasarana \\
\hline Zona Sempadan Pantai & $\begin{array}{l}\text { Menara Pemantau, Gazebo, Toilet dan tempat bilas, } \\
\text { Musholla }\end{array}$ & $\begin{array}{l}\text { Vegetasi pantai, } \\
\text { Pesisir pantai, } \\
\text { Jalan setapak, Jalur } \\
\text { sepeda dan } \\
\text { Jogging Track }\end{array}$ \\
\hline Zona 1 & $\begin{array}{l}\text { Parkir Kendaraan (Mobil, Motor \& Buas), Penyewaan } \\
\text { Sepeda, Parkir Sepeda, Plaza (Pusat Kuliner), ATM } \\
\text { Center, Pos Keamanan, Kantor Pengelola dan Karantina } \\
\text { Penyu, Klinik, Penyewaan alat wisata Air (surfing), TIC } \\
\text { dan Kantor Agent Wisata, Lapangan Outdoor, Toilet dan } \\
\text { Tempat Bilas, Musholah, Pusat Souvenir, Gerbang Masuk } \\
\text { dan Keluar, Balai Seni Budaya, Menara Pemantau, } \\
\text { Camping Ground \& Outbond, Homestay, Tempat } \\
\text { Rehabilitasi Terumbu Karang dan Kolam Alami untuk } \\
\text { alternatif sumber air / penampungan air. }\end{array}$ & \multirow{2}{*}{$\begin{array}{l}\text { RTH, } \\
\text { Evakuasi, } \\
\text { penambahan lebar } \\
\text { jalan, penambahan } \\
\text { penerangan } \\
\text { secukupnya, jalur } \\
\text { sepeda, jogging } \\
\text { track, } \\
\text { penyediaan air } \\
\text { bersih } \\
\text { (penampungan } \\
\text { air), gardu listrik, } \\
\text { pengelolaan air } \\
\text { limbah (IPAL) }\end{array}$} \\
\hline Zona 2 & $\begin{array}{l}\text { Penginapan (cottage dan losmen), parkir kendaraan, TIC, } \\
\text { Pos Kemananan, Penyewaan alat wisata air (alat } \\
\text { pancing), Toilet dan Tempat Bilas, Musholah, Klinik, } \\
\text { Gerbang Masuk dan Keluar (Alternatif), Kolam Alami } \\
\text { untuk alternatif sumber air / penampungan air. }\end{array}$ & \\
\hline
\end{tabular}

Sumber: Penulis, 2019

\section{KESIMPULAN DAN SARAN}

\section{Kesimpulan}

1) Pantai Pangumbahan berada di kawasan Geopark Global Ciletuh Palabuhanratu yang diakui UNESCO (United Nations Educational, Scientific and Cultural Organization) sebagai salah satu dari empat Geopark Global di Indonesia

2) Pantai Pangumbahan merupakan wilayah perencanaan dan pembangunan wisata bahari di dalam RIPPARDA (Rencana Induk Pembangunan Kepariwisataan Daerah) berdasarkan Perda Kab. Sukabumi No. 10 Tahun 2010 pasal 49

3) Kawasan wisata Pantai Pangumbahan dibagi menjadi 3 zona yakni zona inti, zona penyangga dan zona pelayanan.

4) Pantai Pangumbahan merupakan salah satu wisata yang dapat memberikan pengalaman sekaligus edukasi terhadap wisatawan yang datang terkait konservasi, budaya dan pentingnya menjaga ekosistem alam.

5) Masyarakat lokal Pantai Pangumbahan memiliki kesempatan untuk menjadi pelaku dan penyedia jasa wisata dilihat dari kearifan lokal, kegiatan wisata baru yang diusulkan hingga penyediaan akomodasi untuk wisatawan

6) Perencanaan dan penataan kawasan wisata Pantai Pangumbahan yang dilakukan mengedepankan kelestarian alam dan perekonomian masyarakat sekitar.

\section{Saran}

1) Masyarakat harus memanfaatkan potensi lapangan kerja yang tercipta dari kegiatan wisata di Pantai Pangumbahan dengan optimal dan harus sadar akan pentingnya konservasi sumber daya alam sehingga wisata Pantai Pangumbahan berkelanjutan.

2) Wisatawan harus ikut serta dalam menjaga keberlangsungan pariwisata Pantai Pangumbahan dengan berkontribusi dan berperilaku positif terhadap alam sekitar Pantai Pangumbahan sebagai salah satu wujud pelestarian alam.

3) Pengelola harus terus mengembangkan ide wisata dengan berinovasi dan mempertimbangkan kebutuhan wisatawan serta partisipasi masyarakat. 
4) Pemerintah harus terus mendorong wisata Pantai Pangumbahan sebagai salah satu wisata andalan khususnya di Kabupaten Sukabumi sehingga kegiatan pariwisata di Kawasan Pangumbahan dan sekitarnya berkembang serta mendorong peningkatan PAD (Pendapatan Asli Daerah)

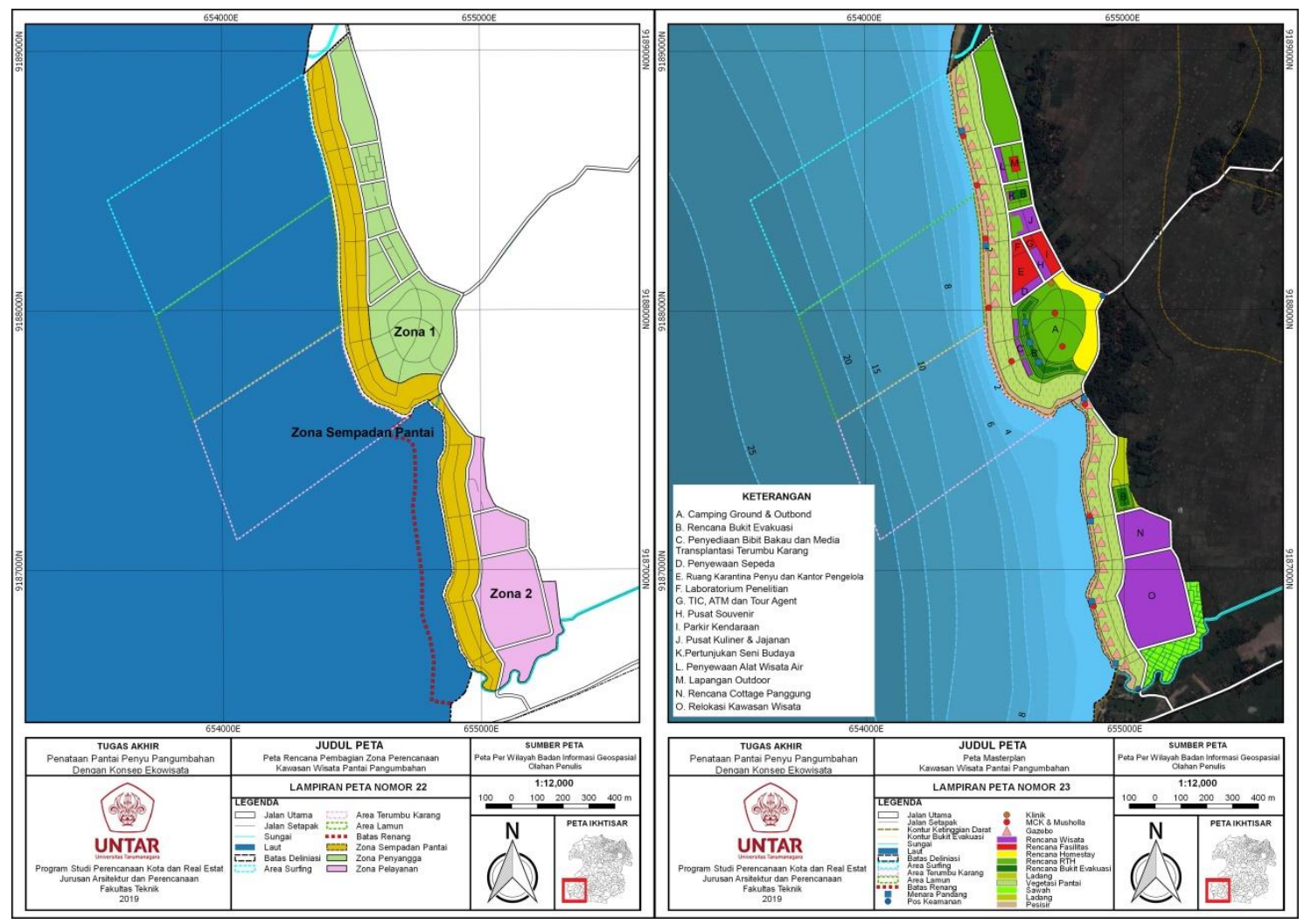

Gambar 1. Peta Pembagian Zona dan Masterplan Pantai Pangumbahan Sumber: Penulis, 2019

\section{REFERENSI}

Atmaja, E. (2010). Wilayah Pesisir (Coastal Zone). Jurnal Ilmu dan Teknologi Kelautan Tropis.

Baud B., M. (1997). Tourism and Recreation Development. Great Britain: The Architectural Press Ltd.

Gold, S. (1980). Recreation Planning and Design. New York: Mc Graw Hill Book Company.

Goodwin. (1997). Terestrial Ecotourism : Planning Sustainable Tourism. Bandung: ITB.

Inskeep, E. (1991). Tourism Planning : An Integrated and Sustainable Development Approach. New York: Van Nostrand Reinhold.

Moore, A. D. (2005). Ecotourism Development : A Manual for Conservation Planners and Managers. Arlington, Virginia, USA: The Nature Conservancy.

Nyoman S. P. (2002). Ilmu Pariwisata Sebuah Pengantar Perdana. Jakarta: Pradya Paramita.

Silver, C. (1997). Urban Based Ecotourism in Indonesia. Bandung: ITB.

Yoeti, O. A. (1982). Perencanaan Strategis Pemasaran daerah Tujuan Wisata. Jakarta: PT Pradnya Paramita.

Permendagri No. 33, Pasal 2 (2009). Prinsip Pengembangan Ekowisata Berbasis Masyarakat dan Konservasi. 
